
\title{
25 Research Square \\ Lymphoepithelial carcinoma in the body of the tongue: The first case report
}

Ono Sawako ( $\square$ de19008@s.okayama-u.ac.jp)

Okayama University Hospital: Okayama Daigaku Byoin

\section{Hidenori Marunaka}

Okayama Daigaku Byoin

\section{Hiroyuki Yanai}

Okayama Daigaku Byoin

\section{Hotaka Kawai}

Okayama University: Okayama Daigaku

\section{Kiyofumi Takabatake}

Okayama University: Okayama Daigaku

\section{Keisuke Nakano}

Okayama University: Okayama Daigaku

\section{Kenji Nishida}

Okayama Daigaku Byoin

Kohei Taniguchi

Okayama Daigaku Byoin

\section{Tomohiro Toji}

Okayama Daigaku Byoin

\section{Hitoshi Nagatsuka}

Okayama Daigaku Byoin

\section{Tadashi Yoshino}

Okayama Daigaku Byoin

\section{Case Report}

Keywords: Lymphoepithelial carcinoma, oral cavity, body of the tongue

Posted Date: December 15th, 2020

DOI: https://doi.org/10.21203/rs.3.rs-127893/v1

License: (c) (i) This work is licensed under a Creative Commons Attribution 4.0 International License. Read Full License 


\section{Abstract \\ Background}

Lymphoepithelial carcinoma (LEC) of the tongue is a rare subtype of squamous cell carcinoma. Histologically, it is an undifferentiated carcinoma with rich lymphocyte and plasma cell infiltration. The most common location for LEC in the head and neck is the salivary glands, and LEC of the oral cavity is extremely rare ${ }^{1}$.

\section{Conclusions}

The first case report of LEC in the body of the tongue is presented. In addition, a review of the literature was performed, and the relationship between LEC and Epstein-Barr virus infection was considered.

\section{Introduction}

Lymphoepithelial carcinoma (LEC) is a squamous cell carcinoma morphologically similar to nonkeratinizing nasopharyngeal carcinoma, undifferentiated subtype ${ }^{1}$. Schminke first described LEC of the nasopharynx in 1921. Histologically, LEC consists of atypical epithelial-derived cells that have pale cytoplasm and large-round vesicular nuclei. It is characterized by lymphoid cells breaking up the tumor into tiny aggregates. Epstein-Barr virus (EBV) is associated with head and neck LEC (HNLEC).

HNLEC is a tumor diagnosed most commonly in the salivary glands, and only 17 cases in the oral cavity appear to have been reported so far. To the best of our knowledge, no case of LEC in the body of the tongue has been reported in the English literature. A case of LEC in the body of the tongue is presented, along with a review of the literature on oral LEC and a discussion of the relationship between oral LEC and EBV infection.

\section{Case Report}

An 82-year-old man with a previous history of alcohol and tobacco use and esophageal cancer 8 years earlier noticed a mass on the left edge of the tongue. Malignancy was suspected on examination of a biopsy specimen, and he was referred to our hospital. On clinical examination, a hard, slightly bulging mass with a smooth surface, approximately $2 \times 1 \mathrm{~cm}^{2}$, was found (Fig. 1). The tumor was localized in the posterior edge of the left side of the tongue, and there was no cervical lymph node enlargement on computed tomography (CT) (Fig. 2). The nasal cavity, nasopharynx, and larynx appeared normal on endoscopy. The tumor was resected, and macroscopically, the excised tumor was a pale yellowish, solid mass, $1.7 \times 1.0 \times 1.2 \mathrm{~cm}^{3}$ in size (Fig. 3). Histologically, the tumor cells showed proliferation of pale staining, cohesive epithelial cells with prominent surrounding and infiltrating lymphocytes (Fig. 4). The tumor cells contained large round vesicular nuclei with prominent nucleoli. On immunohistochemistry, the tumor cells were positive for cytokeratin AE1/AE3, p40, and p53. On in situ hybridization, the epithelial 
cells were negative for EBV-encoded small RNA (EBER) (Fig. 5). The diagnosis of LEC was made. After surgery, no recurrence was observed at the 7-month follow-up visit.

\section{Discussion}

LEC is a subset of poorly differentiated squamous cell carcinoma with intermingled lymphocytes. LEC outside of the nasopharynx is rare, and only 17 cases of oral LEC have been reported (Table 1). Oral LEC developed commonly in the minor salivary gland, lip, and palate. This is the first report of LEC arising in the body of the tongue. The age of patients ranged from 11 to 82 years (average 55.5 years), and there was no sex predilection. All tumors were within $3 \mathrm{~cm}$ (range: 0.5 to $2.6 \mathrm{~cm}$ ) in size. Six patients $(37.5 \%)$ had metastases to the cervical lymph nodes. Although one patient who refused treatment died of tumor 34 months after diagnosis, the prognosis of patients with oral LEC was excellent.

Histologically, the present case showed proliferation of non-keratinized epithelial cells with massive infiltration of lymphocytes. On immunohistochemical examination, tumor cells were diffusely positive for cytokeratin AE1/AE3 and p40. These results confirm the character of the tumor cells as squamous epithelium.

Previous reports showed an association between EBV and oral LEC, especially in Asian cases. Of the 11 Asian cases, 9 were positive. In contrast, no cases in North and South America, Europe, and Africa showed an association with EBV. In the present case, the tumor cells were negative on EBER in situ hybridization.

The tumor cells of the present case showed overexpression of $p 53$. This finding suggests that mutation of TP53 may play a key role in carcinogenesis of this tumor. In the previous studies, p53 status was studied in only 2 cases. One case with EBV showed p53 expression in only $25 \%$ of the tumor cells, suggesting wild type ${ }^{3}$. In contrast, one EBV-negative LEC showed overexpression of p53 on immunohistochemistry ${ }^{4}$. Although the number of cases is limited, there may be different mechanisms of tumorigenesis in oral LEC.

Lymph node metastasis was present in 6 of 18 cases, and it was more common in EBV-positive cases. The EBV status of oral LEC may have some role in nodal metastasis.

In conclusion, the first case of LEC in the body of the tongue was presented. This EBV-negative case might have been caused by TP53 mutation, another possible mechanism of tumorigenesis of oral LEC. To identify prognostic factors, study of additional cases is needed.

\section{Declarations}

\section{Ethics approval and consent to participate}

Not applicable. 


\section{Consent for publication}

Obtained.

\section{Competing interests}

Not applicable.

\section{Acknowledgments}

Not applicable.

\section{Author information (optional)}

Affiliations

Department of Pathology, Okayama University Hospital, Okayama, Japan

Sawako Ono, Hiroyuki Yanai, Kenji Nishida, Kohei Taniguchi, Tomohiro Toji, Tadashi Yoshino

Department of Otolaryngology Head and Neck Surgery, Okayama University Hospital, Okayama, Japan

Hidenori Marunaka

Department of Oral Pathology and Medicine, Graduate School of Medicine, Dentistry and Pharmaceutical Sciences, Okayama University, Okayama, Japan

Hotaka Kawai, Kiyofumi Takabatake, Keisuke Nakano, Hitoshi Nagatsuka,

Department of Pathology and Medicine, Graduate School of Medicine, Dentistry and Pharmaceutical Sciences, Okayama University, Okayama, Japan

Tadashi Yoshino

\section{Funding}

Not applicable.

\section{Authors' contributions}

SO: Pathology fellow responsible of working up the case. Write up of the manuscript and final submission. HY: Pathology professor responsible for interpretation and final diagnosis of case. Review and editing of final manuscript. HN: Oral pathology professor, consultant during the interpretation and getting to the final diagnosis. Review of final manuscript. All authors review and approved the final article. 
Availability of data and materials

Not applicable.

\section{References}

1. Aleksi E Rytkönen, Pasi P Hirvikoski, Tuula A Salo, et al. Lymphoepithelial carcinoma. Two case reports and a systematic review of oral and sinonasal cases. Head Neck Pathol. 2011;5: 327-334

2. Schminke A. Über. lymphoepitheliale Geschwü. Beitr Path Anat. 1921;68: 161-170

3. Lu S, Huang C, Hsiung C. Primary lymphoepithelioma-like carcinoma of minor salivary gland: a case report with immunohistochemical and in situ hybridization studies. Head Neck. 2006;28: 182-186

4. Almeida LY, Silveira HA, Silva EV et al. EBV-negative lymphoepithelial-like carcinoma of the lower lip. Autops Case Rep. 2019;13; e2020138

5. Ahuja AT, Teo PM, To KF, et al. Palatal Lymphoepitheliomas and a review of head and neck lymphoepitheliomas. Clin Radiol. 1999;54: 289-93

6. Chow TL, Chow TK, Lui YH, et al. Lymphoepithelioma-like carcinoma of oral cavity: report of three cases and literature review. Int J Oral Maxillofac Surg. 2002;31: 212-218

7. Tanuja S, Brijesh A, Siddhartha L, et al. Epstein-Barr virus-associated lymphoepithelioma-like carcinoma of mandible. Pediatr Dev Pathol. 2009;12: 152-155

8. Hsieh MY, Chen YK, Lin LM. Primary buccal lymphoepithelial carcinoma: report of a case. Cases Journal TAOMFR. 2010;2: 4-11

9. Zeng M, Li S, Fu J, Wu H, et al. Primary lymphoepithelial carcinoma of the intraoral minor salivary gland: A case report. Oncol Lett. 2015;9: 790-792

10. Weiss LM, Movahed LA, Butler AE, et al. Analysis of lymphoepithelioma and lymphoepithelioma-like carcinomas for Epstein-Barr viral genomes by in situ hybridization. Am J Surg Pathol. 1989;13: 625631

11. Worley NK, Daroca PJ Jr. Lymphoepithelial carcinoma of the minor salivary gland. Arch Otolaryngol Head Neck Surg. 1997;123: 638-640

12. Mahomed F, Grayson W. A rare case of lymphoepithelial carcinoma of the lip. Oral Surg Oral Med Oral Pathol Oral Radiol Endod. 2008;105: e49-52

13. Dardo M, Luigi L, Massimiliano M, et al. Intraoral lymphoepithelial carcinoma of the minor salivary glands. In Vivo. 2012;26: 1087-1089

14. Gultekin M, Sari SY, Gunhan O, et al. Lymphoepithelial carcinoma of the lower lip: report of a case. Int J Hematol Oncol. 2014:24: 70-72

15. Hsiung CY, Huang CC, Wang CJ, et al. Lymphoepithelioma-like carcinoma of salivary glands: treatment results and failure patterns. $\mathrm{Br} \mathrm{J}$ Radiol. 2006;79: 52-55

\section{Tables}


Due to technical limitations, table 1 is only available as a download in the Supplemental Files section.

\section{Figures}
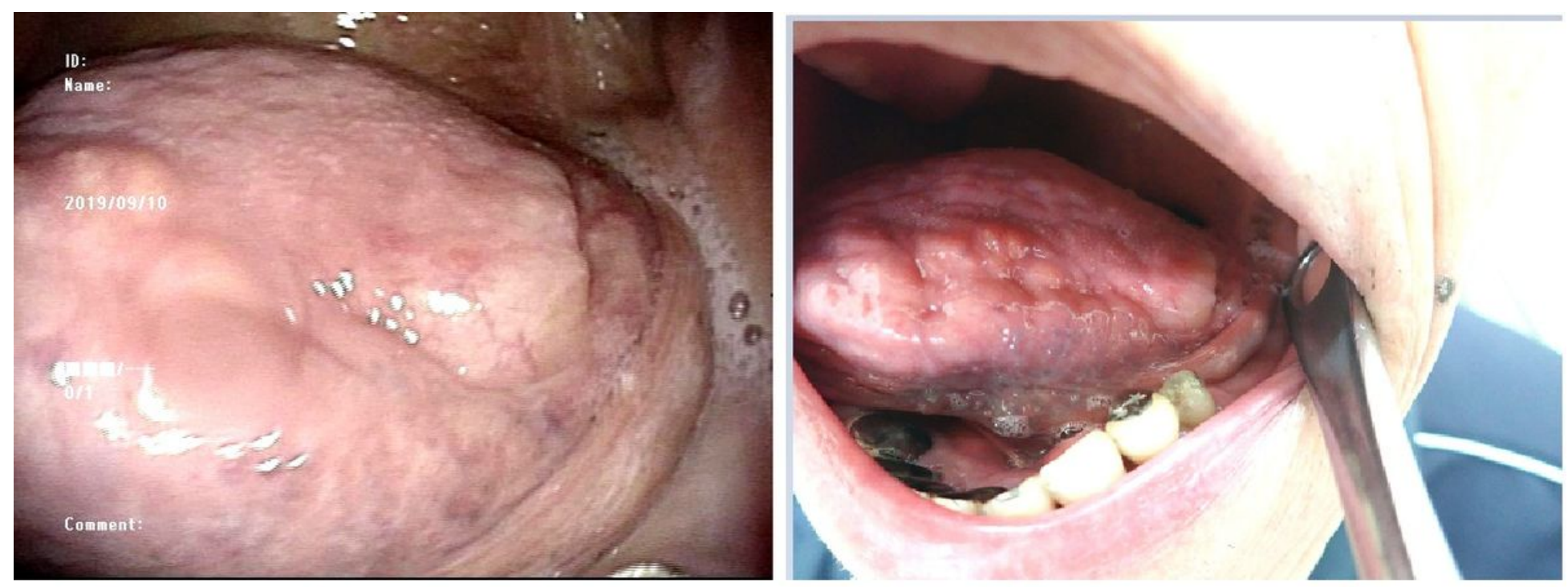

\section{A}

B

\section{Figure 1}

Gross findings of the tumor (a): Intraoral aspect of the tumor. (b): Endoscopic findings of the tumor. The tumor is seen in the posterior edge of the left side of the tongue.
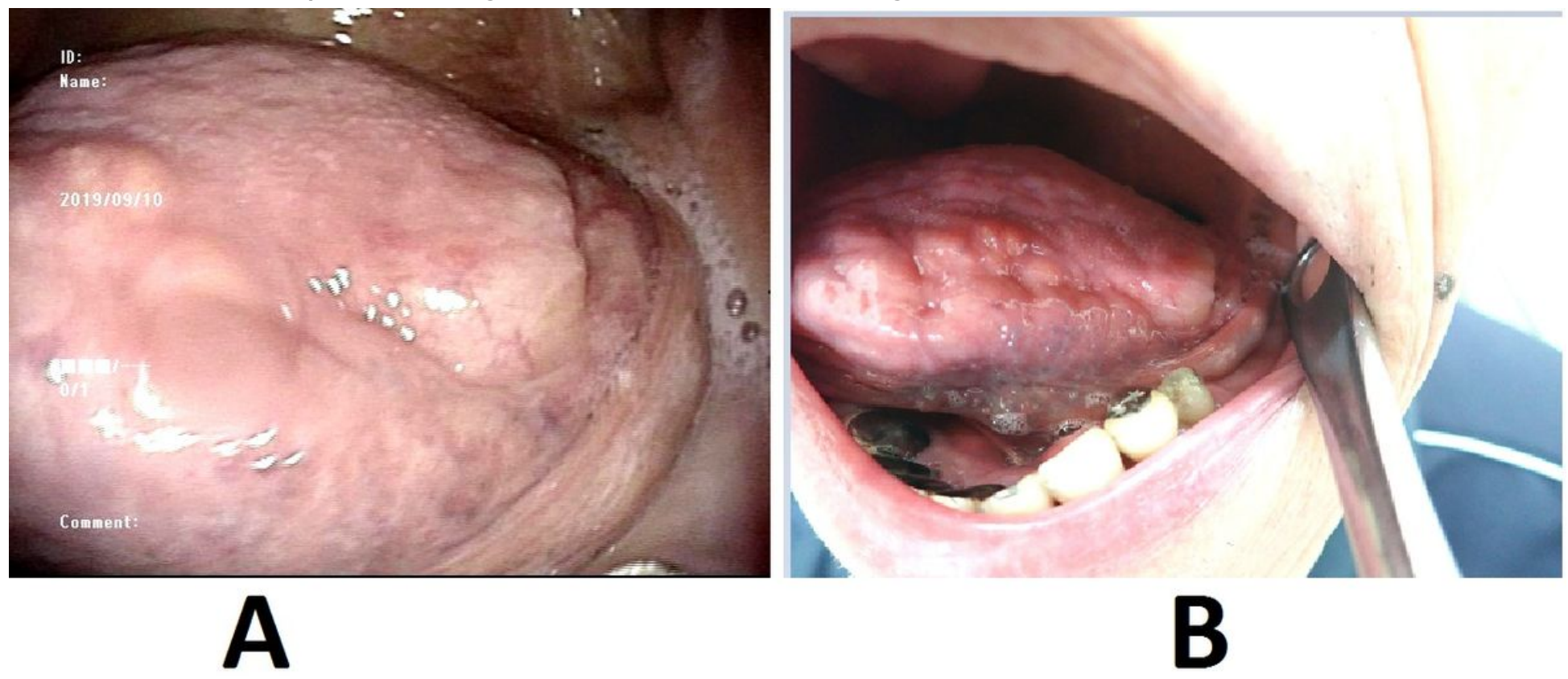

B

\section{Figure 1}


Gross findings of the tumor (a): Intraoral aspect of the tumor. (b): Endoscopic findings of the tumor. The tumor is seen in the posterior edge of the left side of the tongue.

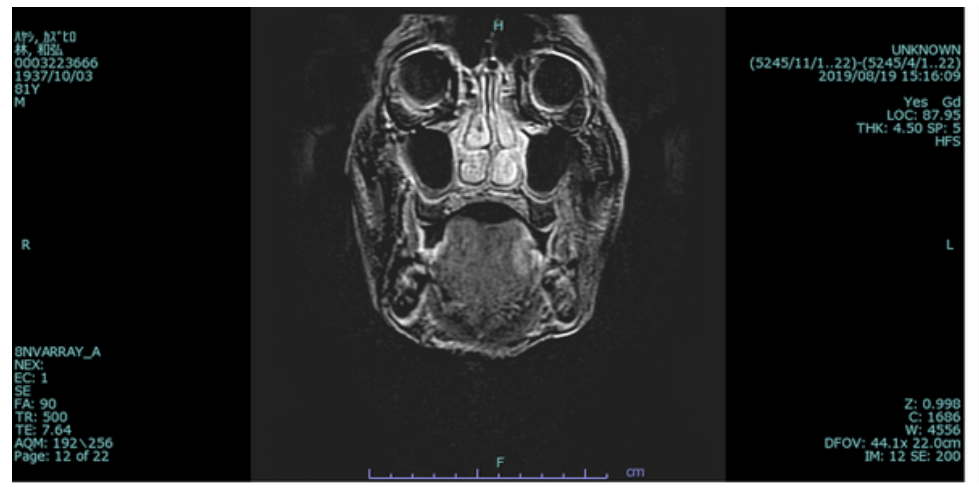

A

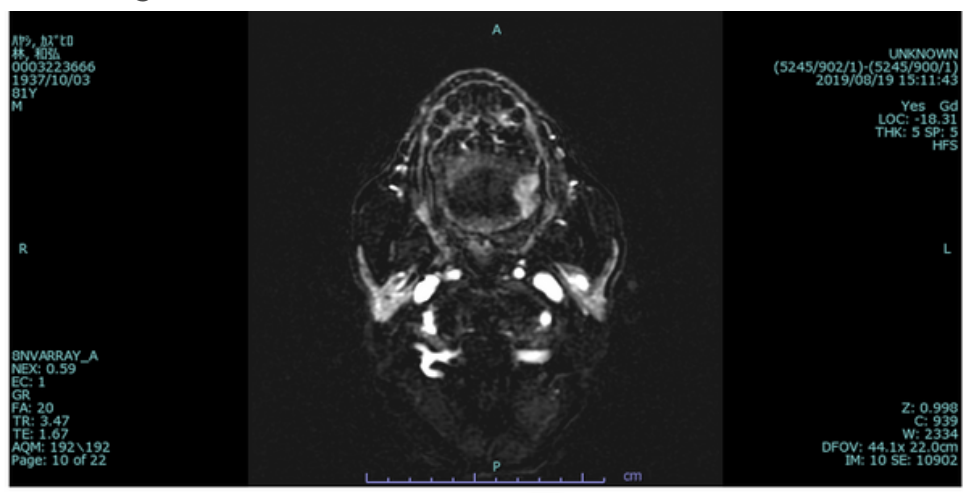

B

\section{Figure 2}

Radiographic findings of the tumor The tumor is localized in the left side of the tongue, and the cervical lymph node is not enlarged.

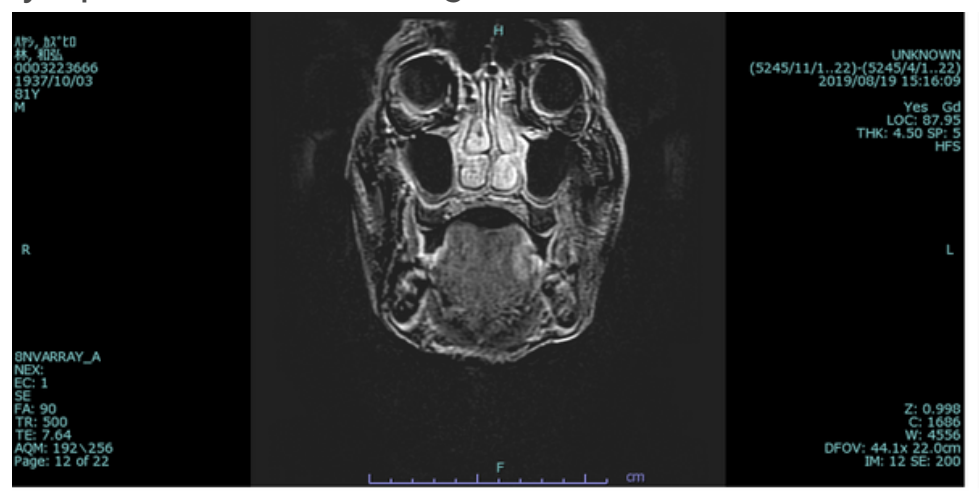

A

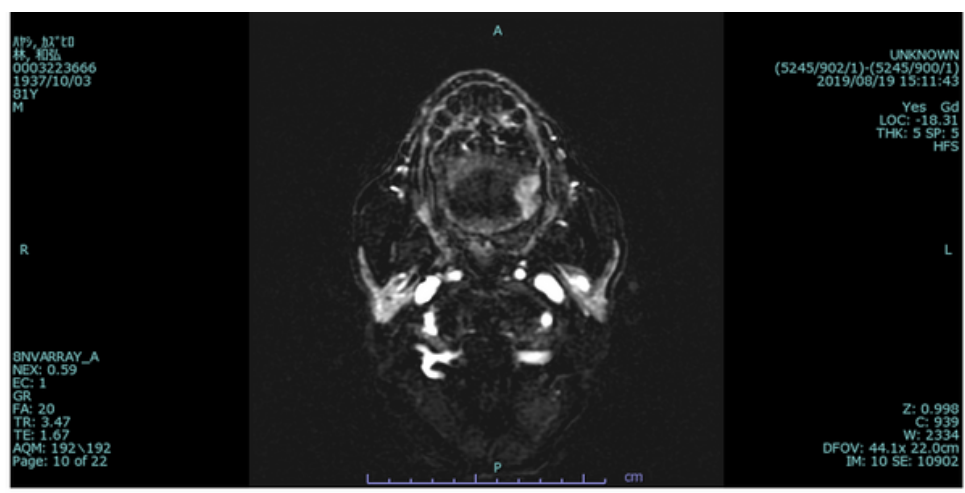

B

\section{Figure 2}

Radiographic findings of the tumor The tumor is localized in the left side of the tongue, and the cervical lymph node is not enlarged. 


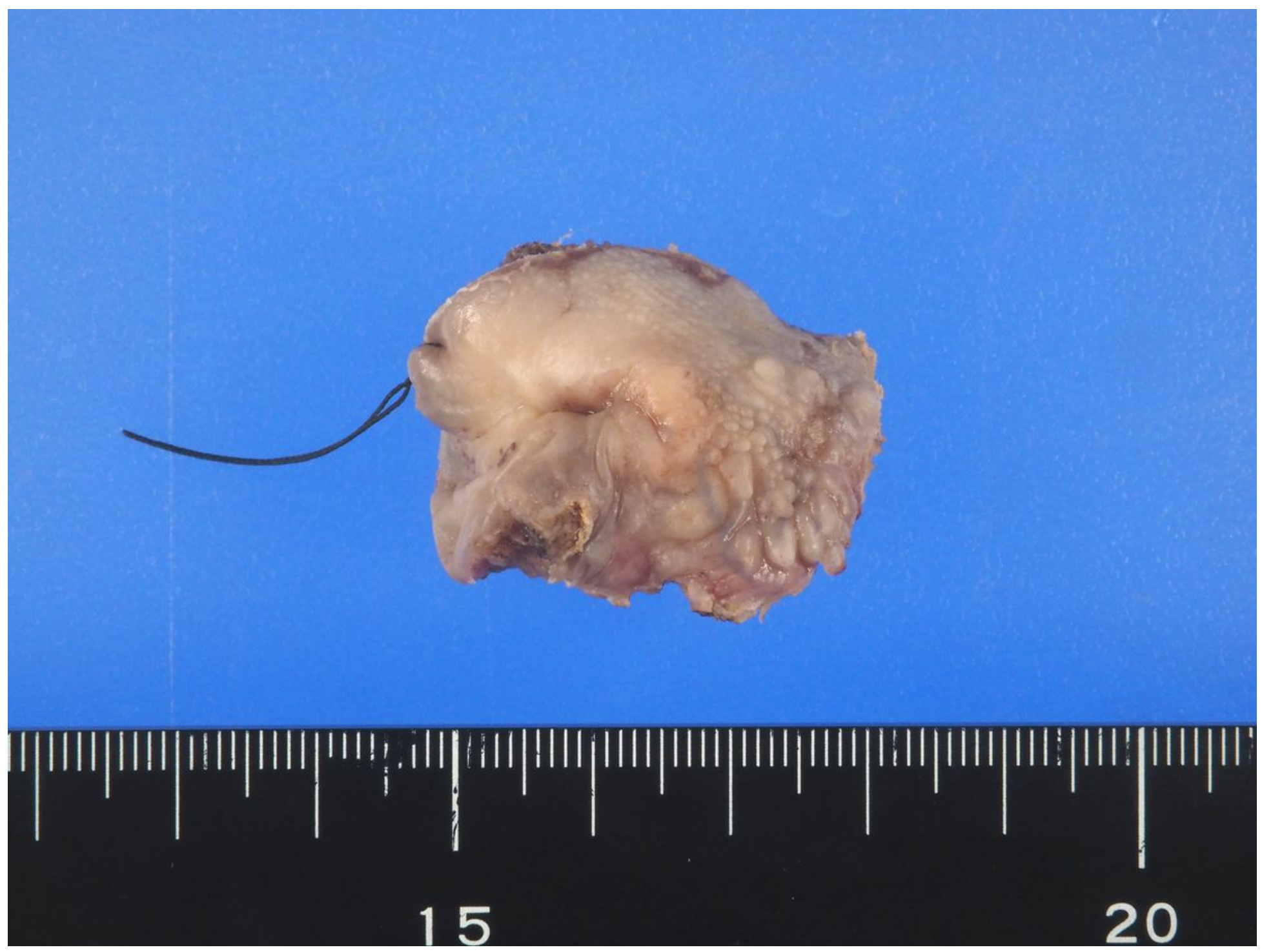

Figure 3

Gross findings of the resected material The tumor is in the anterior vallate papilla. The surface of the tumor is smooth, and the central depression of the tumor is the biopsy scar. 


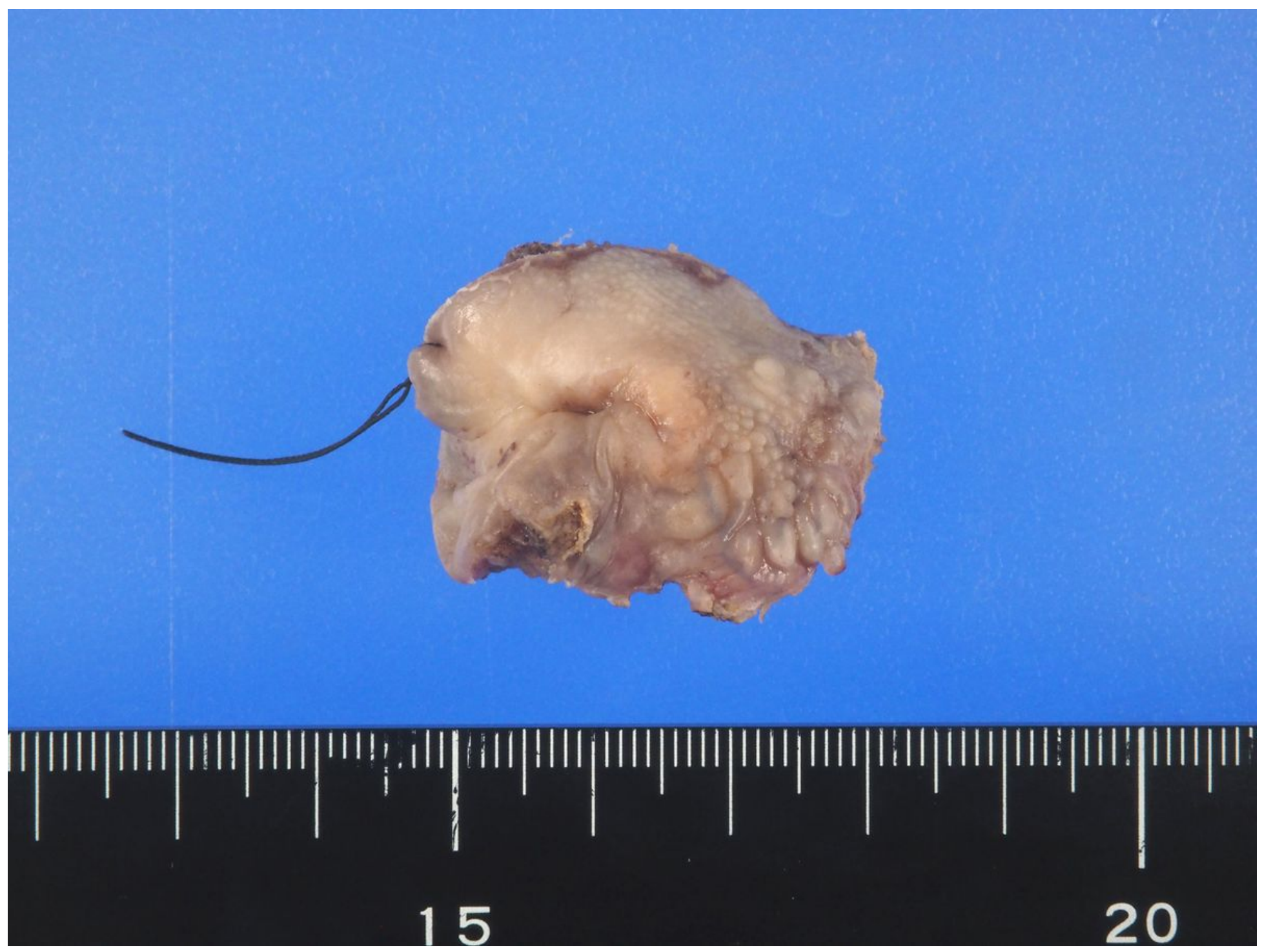

Figure 3

Gross findings of the resected material The tumor is in the anterior vallate papilla. The surface of the tumor is smooth, and the central depression of the tumor is the biopsy scar. 


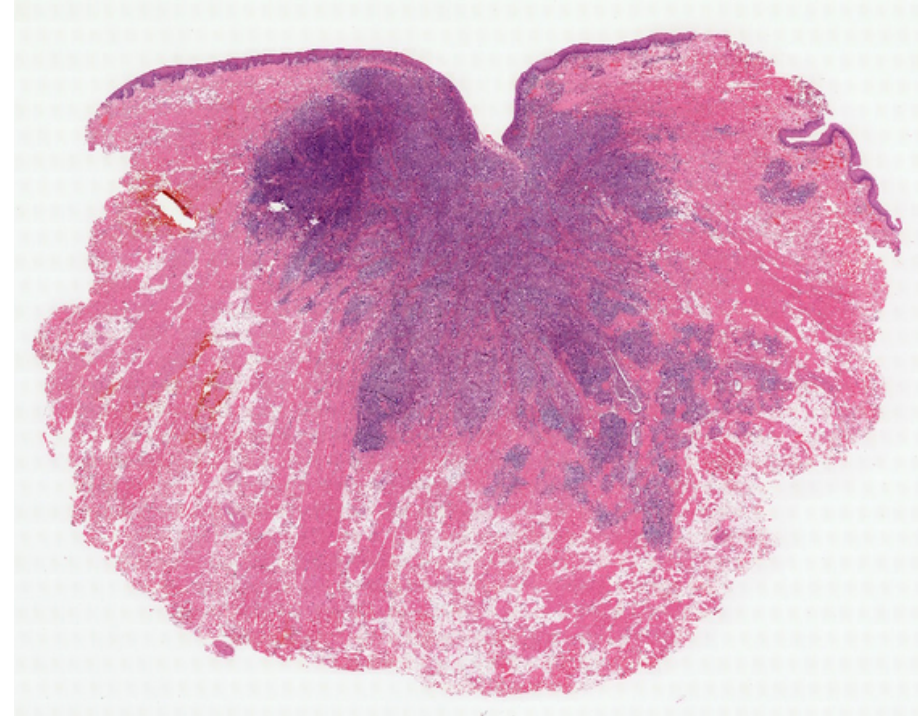

A

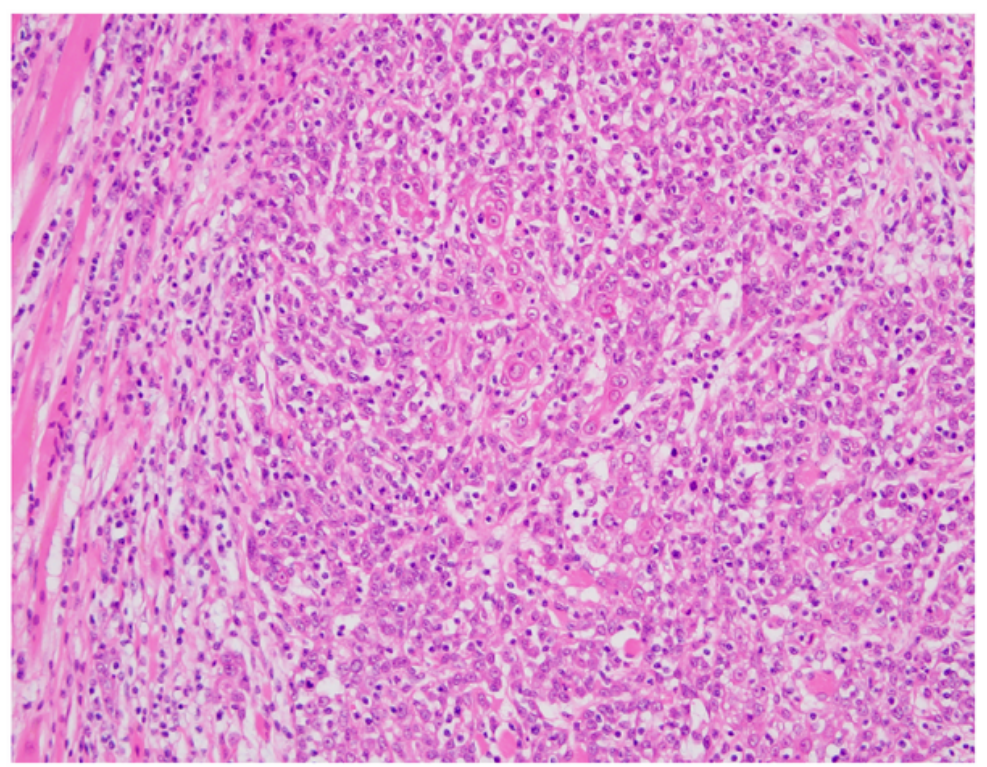

B

\section{Figure 4}

Histological findings of the tumor (a) The tumor invades irregularly to the muscles of the tongue (20x). (b) The tumor cells are polygonal with enlarged vesicular nucleoli and eosinophilic cytoplasm, and abundant infiltration of lymphocytes is seen (200x).

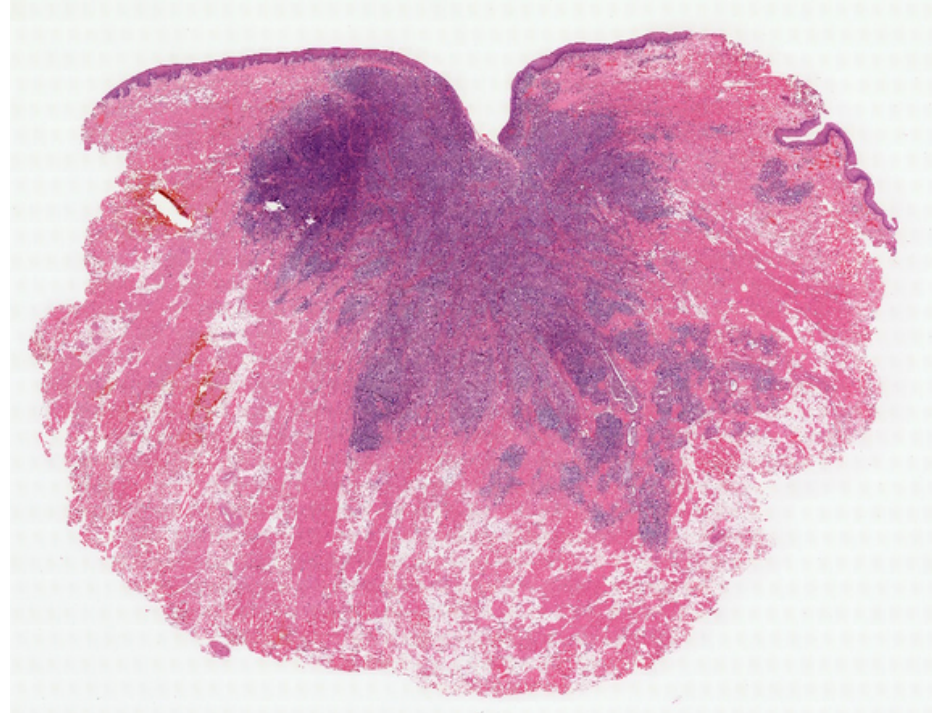

A

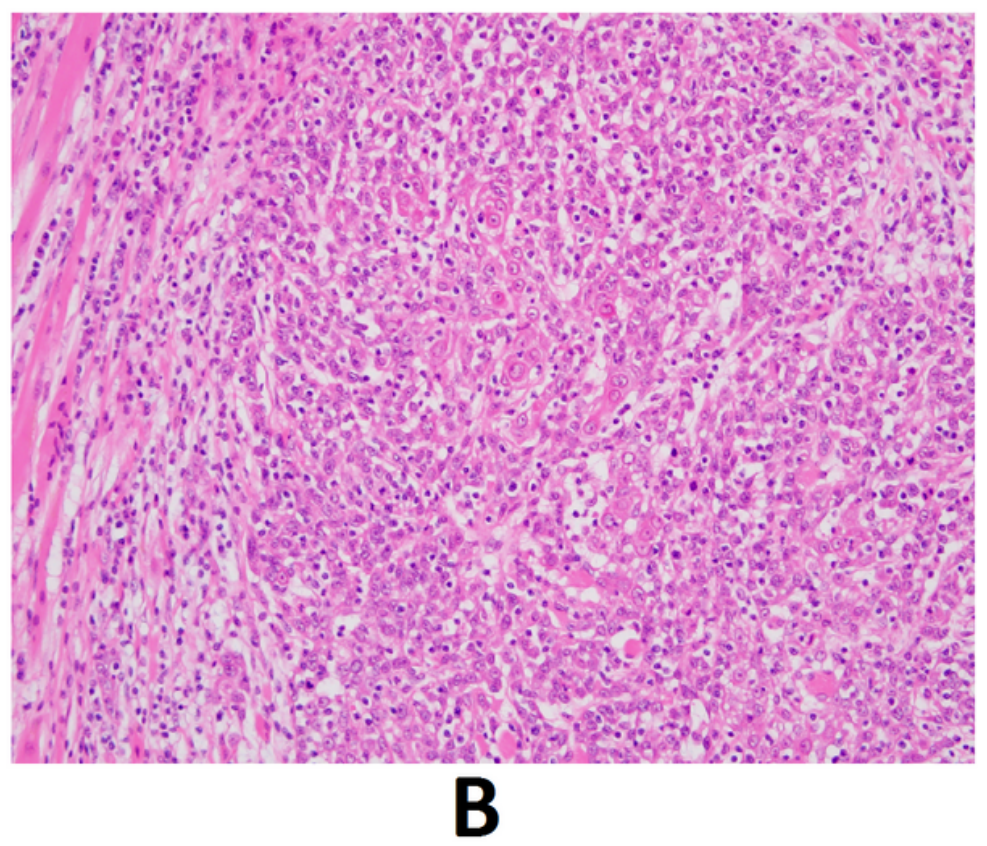

\section{Figure 4}

Histological findings of the tumor (a) The tumor invades irregularly to the muscles of the tongue (20x).

(b) The tumor cells are polygonal with enlarged vesicular nucleoli and eosinophilic cytoplasm, and abundant infiltration of lymphocytes is seen (200x). 


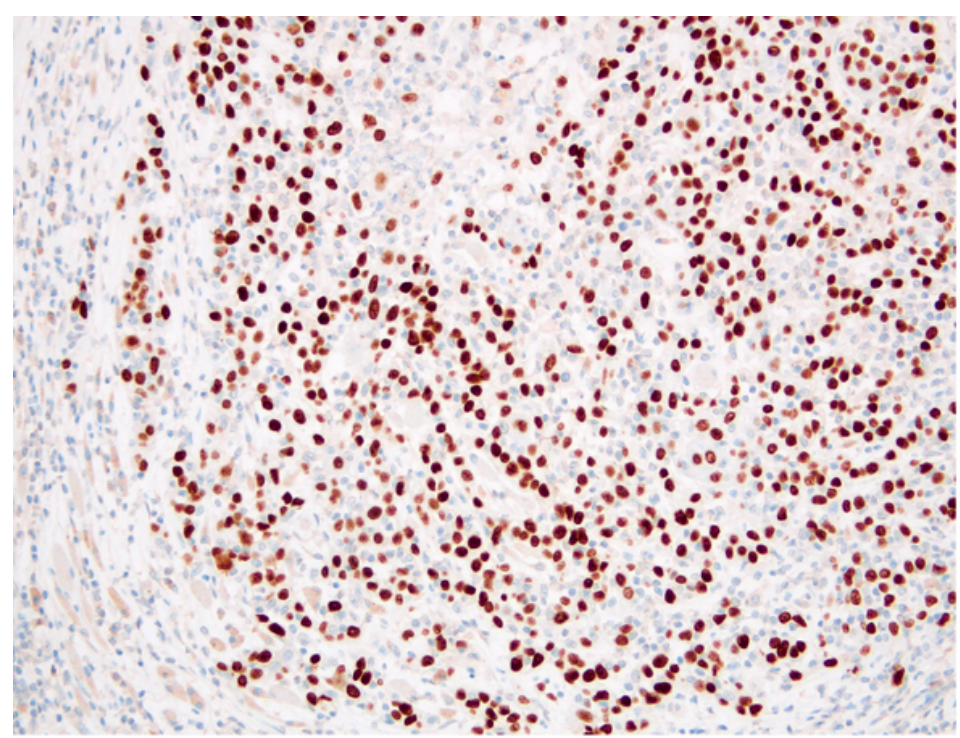

A

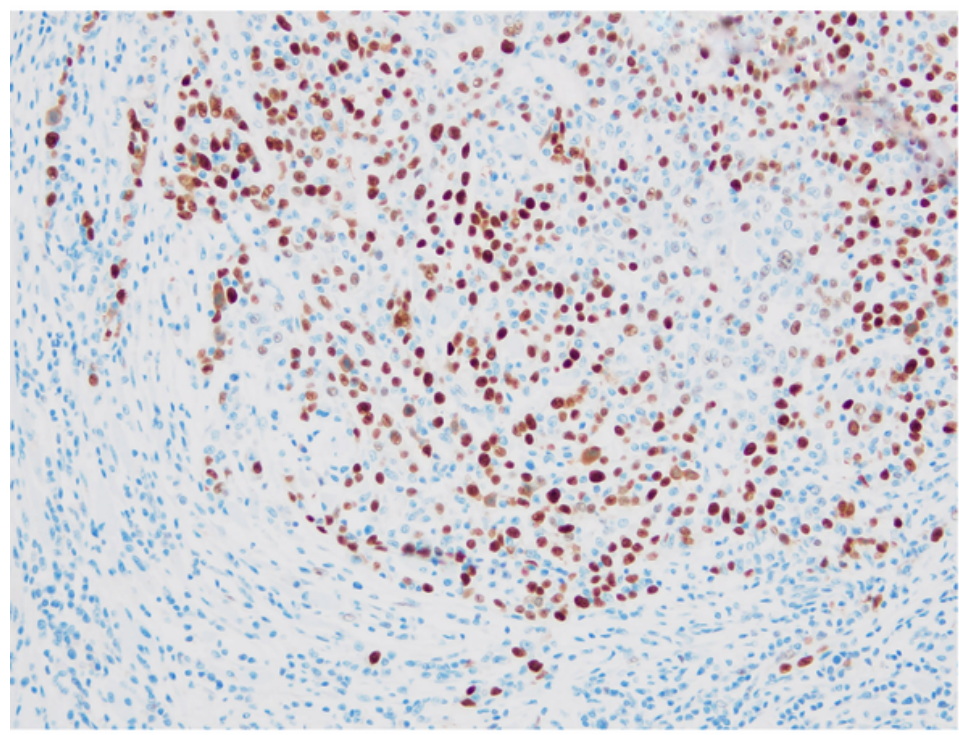

C

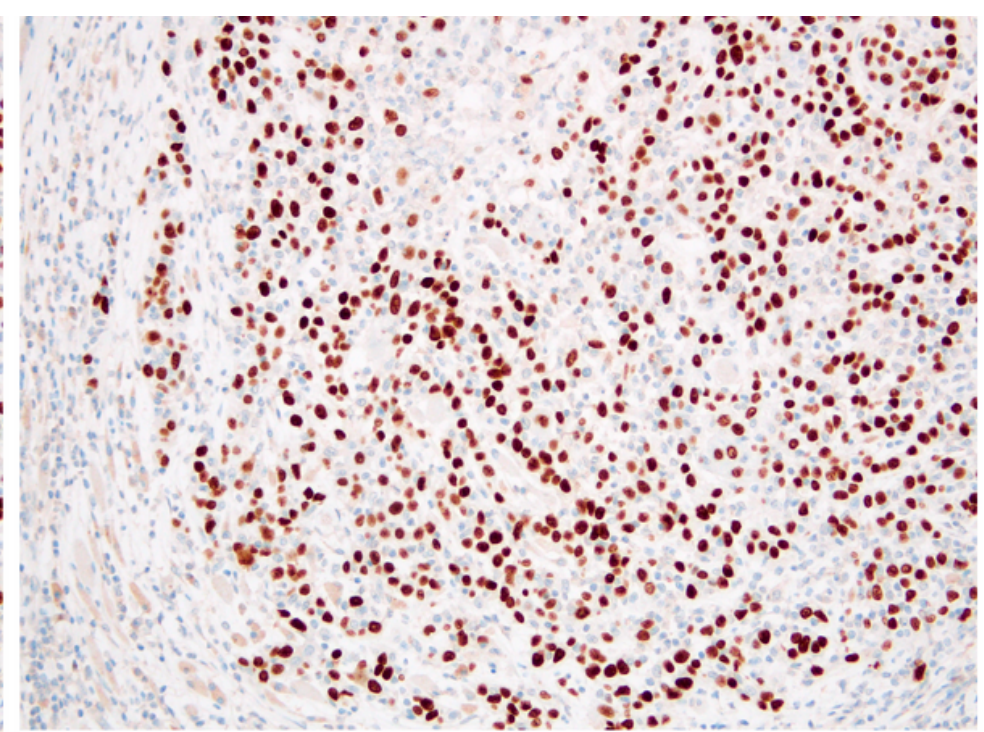

b

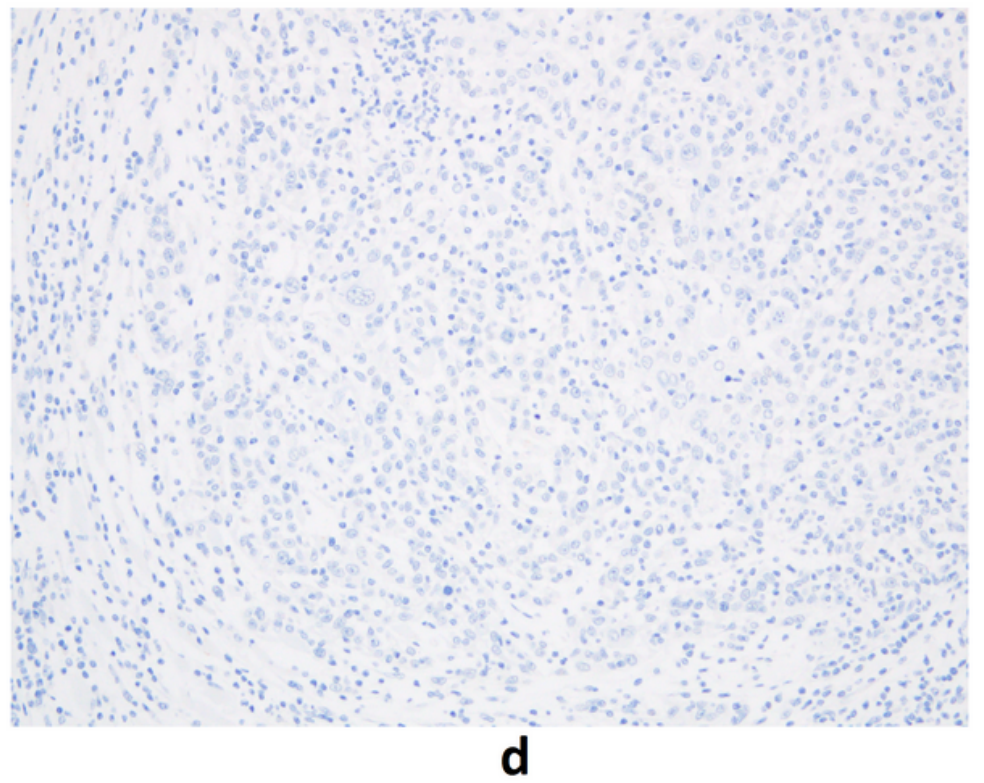

Figure 5

Immunohistochemical and in situ hybridization findings of the tumor On immunohistochemistry, the tumor cells are positive for cytokeratin AE1/AE3(a), p53(b), and p40(c) (200x). The tumor cells are negative on EBER (d) in situ hybridization. 


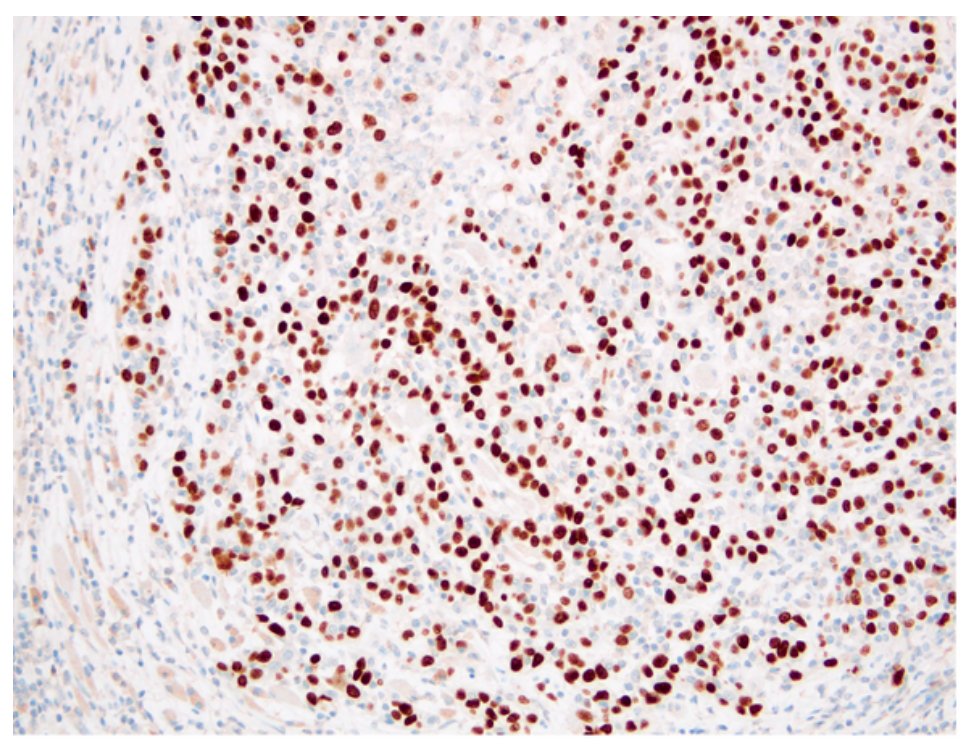

A

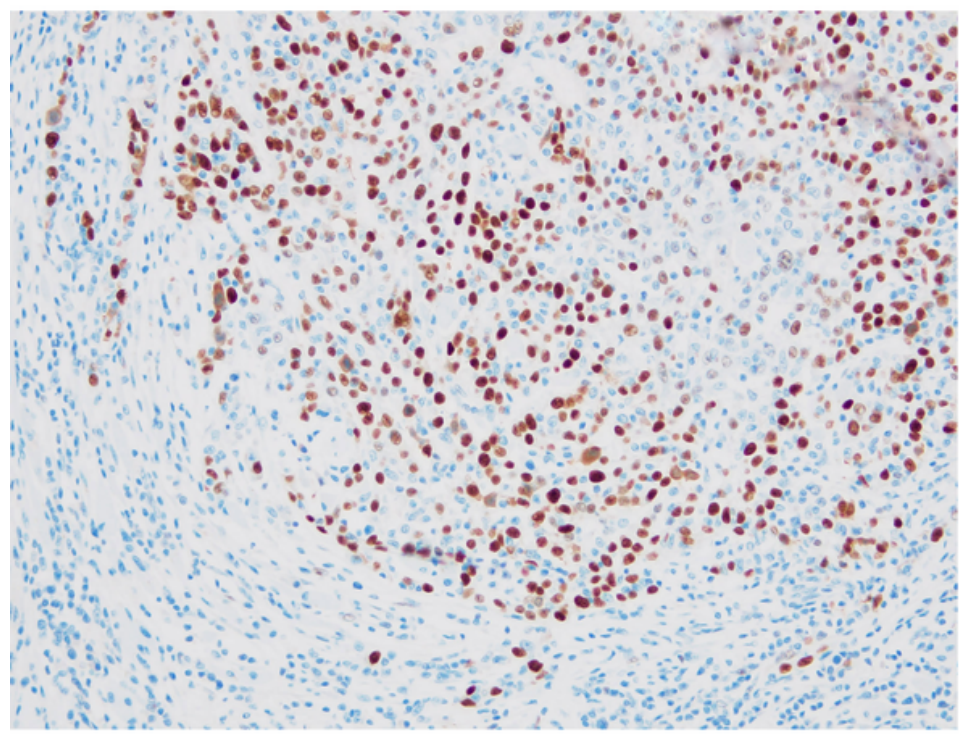

C

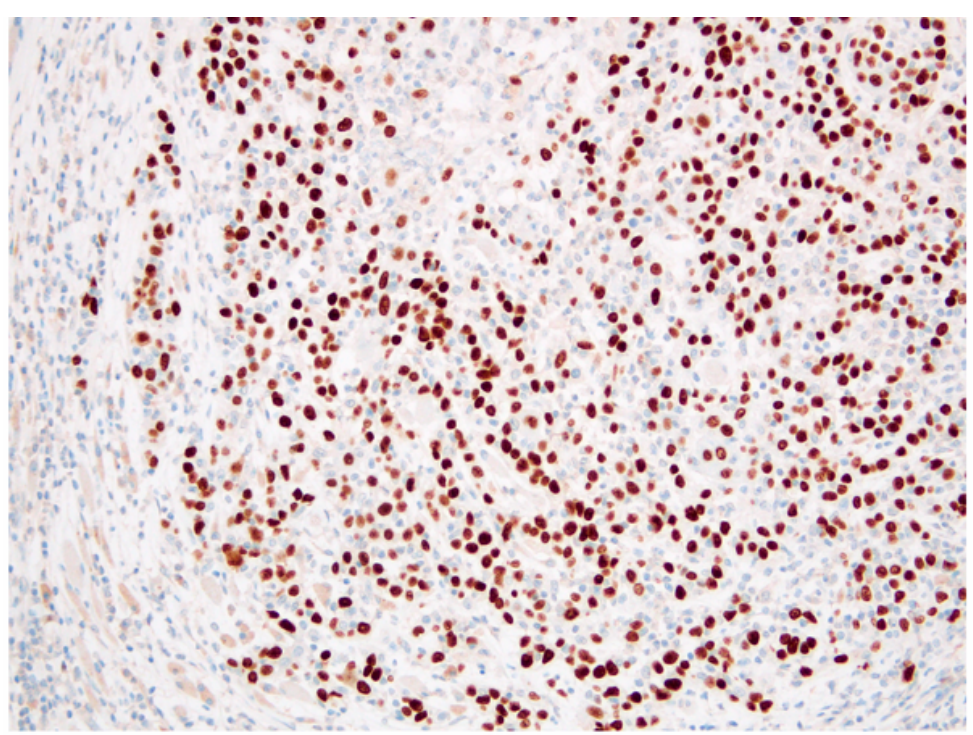

b

d

Figure 5

Immunohistochemical and in situ hybridization findings of the tumor On immunohistochemistry, the tumor cells are positive for cytokeratin AE1/AE3(a), p53(b), and p40(c) (200x). The tumor cells are negative on EBER (d) in situ hybridization.

\section{Supplementary Files}

This is a list of supplementary files associated with this preprint. Click to download.

- table1.xlsx

- table1.xIsx

- checkrist202012030001.pdf 
- checkrist202012030001.pdf

Page 13/13 